since initial implementation, which is a difficulty of sustaining quality improvements over a large time scale. Ways to improve/sustain the improvement need to be explored, with suitable patients identified prior to the weekend effectively. The improvement shown in this study provides evidence for expansion of weekend discharge ward rounds to other trusts, enabling regions and the NHS as a whole to get well patients home, and provide improvements in bed flow and cost savings for the NHS.

\section{IMPROVING THE PARTICIPATION OF HEALTHCARE PROFESSIONALS IN CONTINUING MEDICAL EDUCATION ACTIVITIES (CMES) IN ANURADHAPURA DISTRICT IN NORTHCENTRAL PROVINCE - SRI LANKA}

Nuwan Premawardana. Teaching Hospital Anuradhapura, Sri Lanka

\subsection{6/leader-2019-FMLM.60}

Background Teaching Hospital Anuradhapura[THA] is the largest tertiary care hospital in Anuradhapura district(1100000 population, area $7179 \mathrm{~km}^{2}$ with 82 health institutions). I held presidency of Anuradhapura Clinical Society(ACS), which is the leading clinical academic society in Northcentral Province and led the council(two secretaries, two treasurers and 46 council members) in 2018/2019. Main objective of ACS is to organise CMEs for healthcare professionals in the district(92 specialists \& 357 doctors). Poor participation was evident especially from peripheries. Lack of awareness about CMEs, logistical difficulties to travel, difficulties in getting time-off were identifiable causes.

Aims Improve participation of healthcare professionals of the Province in CMEs at THA.

Methods Repeated discussions with the council members, administrators and medical officers covering all institutions were used to get ideas and feedback. Multiple interventions were implemented such as, innovative methods to increase awareness of CMEs(internet based social media, posting information flyers, phone reminders), supporting to get time-off, pre-arranged transportation for peripheral doctors, engaging target group in organising(giving ownership) and methods to attract participants. Involvement of eminent speakers, use of accessible and attractive external venues, organising events for other staff were done.

Results Number of CMEs organised increased from 18 to 29 (2018/19). Mean number of participants for an event increased from 62 to 91. Participation of doctors from peripheries and THA increased. Participation of peripheral doctors increased by 19.2 fold compared to $2017 / 18.378$ other health professionals participated (54.7\% from peripheries).

Conclusions In comparison to 2017/18, participation and enthusiasm among health professionals about CMEs increased. Perseverance and innovation with maximum membership involvement, teamwork and multisectoral collaboration contributed to success.

\section{IMPROVING THE RELIABILITY OF PHYSICAL OBSERVATIONS MONITORING ON AN INPATIENT PSYCHIATRIC WARD}

Liam Loftus. FY2 Doctor, Royal Liverpool and Broadgreen University Hospitals NHS Trust
Mersey Care NHS Foundation Trust Policy states that as a minimum, all psychiatry inpatients should have their physical observations 'undertaken and documented weekly'. Consensus amongst staff at Rathbone Rehabilitation Centre, a 26-bed psychiatric rehabilitation facility, was that compliance was sub-optimal. Staff were concerned that failing to monitor the vital signs of our patients would reduce the early detection of illness in our particularly vulnerable patient group.

In the 6-week pre-intervention period, the percentage of patients having their observations measured each week ranged from $29 \%$ to $71 \%$, with a median of $52 \%$. Conversations across the MDT exposed three significant barriers to compliance:

1. Staff knowledge and education

2. Workforce weekly schedules

3. Method of recording observations

I implemented a series of interventions to overcome the above barriers:

1. I held conversations with all staff involved with undertaking observations to ensure that they were aware of both the guidelines, and the positive impact that adherence has upon patient care.

2. I therefore worked alongside the Ward Manager to ensure that protected time for staff to complete observations was introduced to the weekly timetable.

3. I introduced simple tick-box sheet at the front of the observation folder so that at a glance, staff could see which observations were still outstanding.

After implementation, we experienced a significant improvement over the following 6 weeks. The percentage of patients having their observations undertaken in any given week ranged from $72 \%$ to $100 \%$, with a new median of $90 \%$. Run chart analysis demonstrated a shift, as all 6 postintervention data points were situated above the initial median of $52 \%$, thereby demonstrating a statistically significant improvement.

This project demonstrated how a series of simple interventions led to a statistically significant increase in our adherence to Trust Policy, and a subsequent improvement in patient care.

\section{INNOVATING AND IMPROVING THE TEACHING PROGRAMME FOR MEDICAL STUDENTS AT ROYAL SURREY COUNTY HOSPITAL}

Mengfei Lu, Andrew Cole, Gavriella Levinson, Prashant Bamania. Royal Surrey County Hospital, UK

\subsection{6/leader-2019-FMLM.62}

Introduction The transition from medical school to the NHS Foundation programme can be challenging. This project aimed to use these standards to improve the service provision and quality of medical student teaching at $\mathrm{RSCH}$ to develop a teaching programme tailored to support final year medical students as they prepare to become the new generation of Doctors.

Methods There were four elements of the teaching program:

1. Mock OSCE: Practical assessment of clinical skills with individualised feedback. 